This is the peer reviewed version of the following article: García, P. , Romero, C. and Brenes, M. (2018), Influence of iron redox state on black ripe olive processing. J. Sci. Food Agric, 98: 4653-4658, which has been published in final form at https://doi.org/10.1002/jsfa.8995.

1 This article may be used for non-commercial purposes in accordance with Wiley Terms and Conditions for Self-Archiving.

2

3

4

5

6

7

8

9 Food Biotechnology Department, Instituto de la Grasa (IG-CSIC), Building 46, Ctra.

\section{Influence of iron redox state on black ripe olive processing}

\author{
Pedro García, Concepción Romero, Manuel Brenes*
}

11

*Correspondence to: Manuel Brenes, Food Biotechnology Department, Instituto de la Grasa (IG-CSIC), Campus University Pablo de Olavide, Ctra. Utrera km 1, 41013-

Seville, Spain. E-mail brenes@cica.es

16 Running title: Iron in black olives 


\section{Abstract}

20 BACKGROUND: The oxidation and polymerization of the phenolic compounds present

21 in black ripe olives give rise to their black shiny colour which is fixed by the addition of 22 ferrous salts such as ferrous gluconate. Among the many variables that can affect the 23 successful of this fixation step, the influence of the $\mathrm{pH}$ on this process was assessed on 24 fruits of the Hojiblanca cultivar processed at pilot plant scale. Hence, the aim of this 25 work was to gain knowledge on the development of this fixation step, in particular on 26 olives that were oxidized with a single alkaline treatment.

RESULTS: It was found that the penetration of the ferric cation into the olive flesh was an extremely slow process and it led to less dark olives. Besides, at a $\mathrm{pH}$ higher than 6 the oxidation of the ferrous to the ferric cation was a very rapid reaction, and olives that were processed with initial $\mathrm{pH}$ adjusted to 4 units had darker colour than those without $\mathrm{pH}$ correction. Ultrafiltration/nanofiltration of oxidized olive solutions spiked with ferric ions or even pure oxidized ferric solutions through membranes of $10 \mathrm{kda}, 3 \mathrm{kda}$ and $1 \mathrm{kda}$ revealed that ferric ions formed high molecular structures that inhibit the penetration of the ion into the olive flesh and therefore the fixation of the black colour.

CONCLUSION: The results presented in this study suggest that the formation of ferric ions during the colour fixation step of black ripe olives must be avoided to get darker olives. Consequently, the initial $\mathrm{pH}$ of the ferrous gluconate solution must be corrected to avoid oxidation of the ferrous to ferric cations during the fixation step. This study

41 will contribute to the improvement of the colour fixation step of black ripe olive 42 processing.

Keywords: Olive, Fe (II), Fe (III), colour, oxidation 


\section{INTRODUCTION}

48 According to the International Olive Council (IOC), global table olive production for the 2015/2016 season accounted for approximately 2.7 million tons, the main commercial types of table olives being the Spanish-style green, the California-style black and the Greek-style black olive. The method of producing black ripe olives was created at the end of the 19th century in the USA, and today they are widely consumed in pizzas and salads, in America and worldwide, due to their attractive black colour. ${ }^{1,2}$

To produce black ripe olives, American processors store the Manzanilla olives in an acidic solution spiked with calcium chloride and sodium benzoate, and after several months, they are submitted to the oxidation process. The darkening step involves successive treatments (3-5) with a dilute solution of sodium hydroxide (lye); after each lye treatment, olives are put in water and air is bubbled through the tank. ${ }^{1}$ The phenolic compounds present in the olive flesh, mainly the o-diphenols hydroxytyrosol and caffeic acid, are oxidized under the alkaline conditions to produce coloured polymers responsible for the appreciated black colour of these olives. ${ }^{2}$ However, this process generates a high volume of wastewaters (lyes and washing waters), ${ }^{3}$ and a new method with a single lye treatment has recently been put forward. ${ }^{4}$

After the darkening step, olives are currently destoned, washed, canned and sterilized, and they can undergo discolouration. Hence, the use of ferrous gluconate and lactate is legally permitted to fix the colour. ${ }^{5} \quad$ Both iron salts are effective in preventing colour deterioration although ferrous gluconate is most widely employed worldwide. ${ }^{6,7}$ The iron-phenol complexes formed are very stable and the black colour of the olives can be preserved even during their shelf-life of three years. ${ }^{8}$

The interaction between iron species and phenolic compounds has been extensively studied although results are sometimes contradictory. Chelation of simple phenols such as hydroxytyrosol and caffeic acid by Fe (II) has been documented, ${ }^{9}$ but also the interaction between Fe (III) and the flavonoids catechin and quercetin. ${ }^{10}$ Catrouillet et al proposed that the complexation of $\mathrm{Fe}$ (II) with humic acids is $\mathrm{pH}$ dependent, ${ }^{11}$ the ion being mainly adsorbed onto carboxylic groups at acidic $\mathrm{pH}$ and phenolic groups at alkaline $\mathrm{pH}$. Moreover, it has been reported that phenolic compounds 
77 bind first to Fe (II) and then the Fe (II)-polyphenol complex autoxidizes to Fe (III) in

78 the presence of oxygen, ${ }^{12}$ and this has been the mechanism suggested for colour fixation

79 in black ripe olives. After the darkening step, olives are covered with a $0.5-1.5 \mathrm{~g} \mathrm{~L}^{-1}$

80 ferrous gluconate solution that allows the penetration of the ferrous ions into the olive

81 flesh for the formation of the polyphenol-Fe (II) complexes that oxidizes to Fe (III) in

82 the interior of the fruit. ${ }^{7}$ However, the oxidation of ferrous ions is a more rapid reaction

83 than binding to phenolic compounds so the mechanism of colour fixation in black olives

84 by iron species remains unclear. ${ }^{13}$

85

86 MATERIALS AND METHODS

\section{Test to know the effect of iron on non-oxidized olives}

88 Fruits of the Hojiblanca cultivar (Olea europaea L.) stored for six months in industrial 89 tanks at the Agrosevilla SCA factory under acidic conditions were used for the assays. ${ }^{14}$ 90 They had a pH of around 4 units and 3\% salt concentration. One kilogram of the olives 91 was covered directly with $1 \mathrm{~g} \mathrm{~L}^{-1}$ ferrous gluconate solution $(1 \mathrm{~L})$. Subsequently, the 92 mixture was aerated for 24 hours, and the colour $\left(\mathrm{R}_{700}\right)$ was measured.

93 Standard oxidation process of black ripe olives

94 Olives were oxidized in four methacrylate horizontal cylindrical containers where air 95 was bubbled along the horizontal base of the cylinder. Temperature was controlled 96 inside the oxidation tanks by a hot/cold thermostatic bath (Selecta, Spain), and the $\mathrm{pH}$ 97 of the liquid by a $\mathrm{pH}$ meter $(\mathrm{pH} / \mathrm{mv}$ Controller 252, Crison, Spain) connected to an 98 automatic dosage system which bubbled $\mathrm{CO}_{2}$ to neutralize the excess $\mathrm{NaOH}$ in the olive 99 flesh. $^{15}$ removed and the olives were placed in tap water for 20 hours. Air was continuously bubbled into the suspension water/liquid, and the $\mathrm{pH}$ of the liquid was maintained at 8.3 units by adding $\mathrm{CO}_{2}$. Another 20 hour cycle with fresh tap water was repeated. 
106

107

108

109

110

111

112

113

114

115

116

117

118

119

120

121

122

123

124

125

126

127

128

129

130

131

132

133

134

135

\section{Effect of $\mathrm{pH}$ correction during the colour fixation step of black olives}

Oxidized olives with a $\mathrm{pH}$ in the flesh of 8.3 units were placed in a $1 \mathrm{~g} \mathrm{~L}^{-1}$ ferrous gluconate solution (Purac Bioquímica, S. A., Barcelona, Spain) without pH correction (5.5 units) or were $\mathrm{pH}$ corrected with acetic acid up to 4 units for six hours. Air was bubbled during the colour fixation step at $20^{\circ} \mathrm{C}$ and experiments were run in duplicate.

The $\mathrm{pH}$ of the olive flesh was analyzed with a pHmeter-Test 10BNC Spear (Eutech Instruments, Malaysia), simply by introducing the electrode tip into the olive.

\section{Colour fixation of black olives with ferrous and ferric ions at $\mathrm{pH} 4.5$}

Oxidized fruits were covered with (i) a ferrous gluconate solution $\left(1 \mathrm{~g} \mathrm{~L}^{-1}\right)$ with $\mathrm{pH}$ adjusted to 4.5 units with acetic acid, and (ii) a ferric gluconate solution $\left(1 \mathrm{~g} \mathrm{~L}^{-1}\right)$ with the $\mathrm{pH}$ also adjusted to 4.5 units. The olives/colour mixture fixation solution was aerated for six hours and the $\mathrm{pH}$ maintained at 4.5 with occasional additions of acetic acid. To obtain the ferric gluconate solution, the $\mathrm{pH}$ of $1 \mathrm{~g} \mathrm{~L}^{-1}$ ferrous gluconate solution was maintained at 8 units with the addition of $2 \mathrm{M} \mathrm{NaOH}$, and the liquid was aerated for 24 hours. Then the $\mathrm{pH}$ was dropped to 4.5 units with $2 \mathrm{M}$ acetic acid.

Influence of $\mathrm{pH}$ on the oxidation rate of ferrous ions in a pure ferrous gluconate solution

Three litres of $1 \mathrm{~g} \mathrm{~L}^{-1}$ ferrous gluconate solution (Purac Bioquímica S. A., Barcelona, Spain) were put into each of the four oxidation chambers described above. Air was bubbled into these solutions for six hours, and their $\mathrm{pH}$ was maintained at 4, 6, 8 and 9 units by adding $2 \mathrm{M}$ acetic acid or $2 \mathrm{M} \mathrm{NaOH}$. Iron species were determined throughout the oxidation process.

\section{Study of the colour fixation with ferrous and ferric ions in washing waters of black} olives

Two litres of liquid at $\mathrm{pH} 8$ from the second washing water of the black olive processing was obtained from an industrial oxidation tank (Agrosevilla S.C.A, Seville, Spain) and transported immediately to the Instituto de la Grasa laboratory (Seville, Spain). Glacial acetic acid was added to $100 \mathrm{~mL}$ of this solution to drop the $\mathrm{pH}$ by up to 4.5 units and it was then mixed with $400 \mathrm{~mL}$ of a solution containing $1 \mathrm{~g} \mathrm{~L}^{-1}$ ferrous gluconate with $\mathrm{pH}$ adjusted to 4.5 with $2 \mathrm{M}$ acetic acid. The mixture was left at $25^{\circ} \mathrm{C}$ for 
136 five hours without aeration. At time 0 and five hours, $10 \mathrm{~mL}$ of the mixture was 137 ultrafiltered through a Ultracel $3 \mathrm{kDa}$ cut-off membrane (Millipore Corp., MA, USA) 138 into an Amicon $50 \mathrm{~mL}$ stirred cell (Merck Group, Darmstadt, Germany) under nitrogen 139 pressure. Iron species and colour of the liquid was analyzed. Assays were run in 140 duplicate.

141 In parallel, $100 \mathrm{~mL}$ of the industrial solution with $\mathrm{pH}$ adjusted to 4.5 units were 142 mixed with $400 \mathrm{~mL}$ of a ferric gluconate solution and left at $25^{\circ} \mathrm{C}$ for five hours without 143 aeration. Colour and iron species were also measured in the non-ultrafiltered and 144 ultrafiltered solutions obtained at time 0 and five hours, as explained above.

145 The ferric solution was also ultrafiltered through Ultracel 1000, 3000 and 10000 146 daltons cut-off membranes, and the total iron was analyzed in the ultrafiltered solutions. 147 Assays were run in duplicate.

148 Analysis of iron species

149 The total iron in the olive flesh was extracted by wet digestion in triplicate. Two grams 150 of exactly weighted triturated flesh were placed in $50 \mathrm{~mL}$ bore-silicate tubes, $25 \mathrm{~mL}$ of 151 nitric acid $(63 \% \mathrm{w} / \mathrm{w})$ were added, and the tubes were covered with funnels. 152 Subsequently, they were placed in a DigiPREPJr (SCP Science, Canada) and kept at $153120^{\circ} \mathrm{C}$ for eight hours. Once at room temperature, the funnels were removed and $5 \mathrm{~mL}$ 154 of a solution (1:4) of nitric acid $(63 \% \mathrm{w} / \mathrm{w})$ and perchloric acid $(60 \% \mathrm{w} / \mathrm{w})$ was added, 155 with part of the liquid being evaporated by heating at $140^{\circ} \mathrm{C}$ for two hours. The 156

The concentration of Fe (III) was obtained from the difference between total iron 166 and Fe (II). 
167

168

169

170

171

172

173

174

175

176

177

178

179

180

181

182

183

184

185

186

187

188

189

190

191

192

193

194

195

\section{Colour measurement of olives}

The surface colour of the fruits was expressed as reflectance at $700 \mathrm{~nm}\left(\mathrm{R}_{700}\right)$ using a BYK-Gardner Model 9000 Color view spectrophotometer (Silver Spring, Md., USA). The data of each measurement were the average of 20 olives. Lower reflectance values indicate darker fruit.

\section{Colour measurement of liquids}

Solutions were centrifuged at $10000 \mathrm{x} g$ for five minutes, and their absorbance spectrum $\left(\lambda_{380}-\lambda_{740}\right)$ was recorded using a Shimadzu UV-vis spectrophotometer, which was equipped with a computer software program to calculate the CIE $L^{*}$ (lightness), $a^{*}$ (redness) and $b^{*}$ (yellowness) parameters.

\section{RESULTS AND DISCUSSION}

\section{Effect of iron on non-oxidized olives}

The additives ferrous gluconate (E-579) and ferrous lactate (E-585) are employed to fix the black colour formed in olives during the oxidation step but no data are available on the effect of iron on non-oxidized olives. ${ }^{5}$ The fruits submitted to aeration for 24 hours in a ferrous gluconate solution only diminished their colour parameter $\left(\mathrm{R}_{700}\right)$ from 41.1 to 35.1, which means that the olives had a light grey colour instead of the current black colour of oxidized fruit that have $\mathrm{R}_{700}$ values below 10-12 units. Therefore, it is necessary to oxidize the phenolic compounds present in the olive flesh, mainly the $o$ diphenols hydroxytyrosol and caffeic acid, to get a coloured polymer responsible for the black colour on this type of olive. ${ }^{1,2,18}$ Then, the ferrous salts are needed to fix the colour formed and to avoid discolouration during the further packing, sterilization and shelf-life steps.

The rest of the assays carried out in this study were aimed at gaining knowledge on this fixation step.

\section{Effect of pH correction during the colour fixation step of black olives}

The initial correction of the $\mathrm{pH}$ of the ferrous gluconate solution had a great effect on the diffusion rate of iron into the olive flesh (Figure 1). The concentration of total iron 
196

197

198

199

200

201

202

203

204

205

206

207

208

209

210

211

212

213

214

215

216

217

218

219

220

221

222

223

224

225

226

227

in the liquid with initial $\mathrm{pH}$ correction diminished rapidly up to $60 \%$ during the first two hours of aeration, whereas in the liquid without initial acidification, the total iron content dropped only $30 \%$, this decline being more marked during the first hour of aeration. The rapid diffusion of total iron into the olive flesh during the assay with the initial $\mathrm{pH}$ of the corrected liquid must be noted, since previous studies indicated a time of more than five hours to stabilize the penetration of the total iron into the fruit. ${ }^{7}$ In our experiments, olives were treated with a single lye of $28 \mathrm{~g} \mathrm{~L}^{-1}$ strength, and previous assays were run with weak lyes of $10-15 \mathrm{~g} \mathrm{~L}^{-1}$, therefore the permeability of the former olives was higher than the latter. At the end of the colour fixation step (six hours), the difference in total iron concentration between the solutions with $\mathrm{pH}$ initially corrected and non-corrected was around $35 \mathrm{mg} \mathrm{L}^{-1}$.

The concentration of Fe (II) decreased in the liquids in a similar manner than total iron (Figure 1). This process was quite fast during the first 1-2 hours, and low differences of about $10 \mathrm{mg} \mathrm{L}^{-1}$ between solutions with and without initial $\mathrm{pH}$ correction were found after six hours of contact.

With regard to Fe (III), the content of this ion increased in the solution without initial $\mathrm{pH}$ correction from $20 \mathrm{mg} \mathrm{L}^{-1}$ to $40 \mathrm{mg} \mathrm{L}^{-1}$, whereas it remained almost constant during the fixation step in the solution with $\mathrm{pH}$ corrected to 4 units. This different behaviour must be related to the evolution of the $\mathrm{pH}$ in the solutions during the fixation process (Figure 2). When the $\mathrm{pH}$ of the ferrous gluconate solution was initially dropped to 4 units, this parameter increased up to 5.5 units after six hours of contact. By contrast, it increased from 5.5 units to 8 units in the solution without any initial correction of the $\mathrm{pH}$, and it probably accelerated the oxidation of the ferrous ions to ferric.

To confirm this hypothesis, pure ferrous gluconate solutions were oxidized from $\mathrm{pH} 4$ to 9 at $20^{\circ} \mathrm{C}$. Results are presented in Figure 3 and they revealed that oxidation of iron at $\mathrm{pH} 4$ is a very slow process and at $\mathrm{pH} 6$ less than $30 \%$ of the initial ferrous ion was converted to ferric after six hours of aeration. As the $\mathrm{pH}$ increased to 8 and 9 units, the oxidation of ferrous ion was a very rapid reaction. Half of the ferrous ions were converted to ferric in just a few minutes, and these findings can explain the formation of ferric ions during the colour fixation step without any initial $\mathrm{pH}$ correction (Figure 1).

However, it remained unclear why the content of this ferric cation in the fixation 
228 solutions did not decrease with time (Figure 1), in particular in the solutions without any 229 initial $\mathrm{pH}$ correction. Indeed, this behaviour of $\mathrm{Fe}$ (III) in the fixation solution was 230 correlated with the low absorption of total iron in the flesh of olives covered with 231 ferrous gluconate without $\mathrm{pH}$ correction (Figure 4). In addition, the superficial colour of 232 fruits submerged in the ferrous gluconate solution with the initial $\mathrm{pH}$ dropped to 4 units 233 was darker, lower $\mathrm{R}_{700}$, than those covered with the ferrous salt without $\mathrm{pH}$ correction 234 (Figure 4). The $\mathrm{R}_{700}$ parameter decreased from 10.8 to 5.8 units in the former olives and 235 to 7.4 units in the latter, therefore a darkening effect was observed during the colour 236 fixation step, and it was more pronounced when the $\mathrm{pH}$ of the ferrous solution was 237 adjusted to 4 units.

\section{Colour fixation with ferrous and ferric ions at $\mathrm{pH} 4.5$}

239 There are no official or regulated conditions for the use of ferrous gluconate solution, 240 therefore olive factories may add the salt directly to the aerated mixture of olives/water 241 or may prepare the salt solution in advance with or without $\mathrm{pH}$ correction. In any case, 242 the results provided in this work suggest that the oxidation of the iron salt must be 243 reduced. In a new experiment, oxidized olives were put in both ferrous and ferric 244 solutions for five hours under aeration and controlled $\mathrm{pH}$ at 4.5 units. As was expected, 245 the $\mathrm{R}_{700}$ parameter of olives submerged in the ferrous solution decreased from 14.2 to 2465.1 units (Figure 5), whereas it remained almost constant in olives covered with the 247 ferric solution. The iron content diminished to a large extent in the ferrous solution but 248 it only decreased by around $25 \%$ in the ferric solution.

These results (Figures 1, 4 and 5) pointed out that the colour of olives did not 250 change with Fe (III) and this cation did not penetrate into the olive flesh. Two questions 251 remained unanswered: (i) why does Fe (III) not penetrate into the olive flesh?; and (ii) 252 does the Fe(III) form coloured complexes with oxidized polymers? An experiment with 253 washing water as a model solution was designed to answer these questions. Results are 254 presented in Table 1. Both ferrous and ferric ions darkened the washing water at time 0 255 of addition and more intensively after five hours of contact, the lightness parameter $\left(L^{*}\right)$ 256 being the more affected by the addition of the iron cations to the olive solution. This 257 parameter decreased from 84.3 in a mixture of washing water/distilled water (1:4) to $258 \quad 63.3$ and 55.4 in the ferrous and ferric solutions respectively after five hours of contact 259 with the washing water (1:4), therefore these findings demonstrated that both iron 
260 species were able to form coloured complexes in olive solutions. Besides, the 261 nanofiltration of both ferrous and ferric solutions/washing water through 3000 daltons 262 gave rise to an increase in brightness close to that of the washing water/distilled water 263 mixture, which suggested that the increase in colour of the solution was mainly due to 264 the formation of Fe-phenolic complexes of high molecular weight.

265

266

267

268

269

270

271

272

273

274

275

276

277

278

279

280

281

282

283

284

285

286

287

288

289

290

With regard to the concentration of iron in the spiked washing waters (Table 1), it must be highlighted that most of the Fe (II) passed through the 3000 daltons pore size membrane. By contrast, the membrane retained most of the Fe (III) and it could explain the low penetration of this cation into the olive flesh (Fig. 1 and 5) due to the formation of high molecular complexes with phenolic polymers. However, a pure Fe (III) solution was nanofiltered through membranes of $10 \mathrm{kda}, 3 \mathrm{kda}$ and $1 \mathrm{kda}$ and it was found that $38 \%, 83 \%$ and $98 \%$ of the initial iron content was retained on the membrane respectively. Consequently, the polymeric structure formed during the oxidation of ferrous gluconate could inhibit the penetration of Fe (III) into olives, although the formation of polymeric Fe (III)-phenolic complexes must not be ruled out.

\section{CONCLUSIONS}

After the oxidation step, the $\mathrm{pH}$ of the olive flesh may range between 7.5 and 8.5 units and it allows for the increase of $\mathrm{pH}$ in the ferrous gluconate solution during the colour fixation step to up to 8-8.5 units. It has been found that at a $\mathrm{pH}$ higher than 6 , the oxidation of the ferrous to ferric cation is a very rapid reaction, so the $\mathrm{pH}$ of the ferrous gluconate solution must be corrected at the beginning of the fixation step to reduce the oxidation of the metal. Surprisingly, the penetration of the ferric cation into the olive flesh was an extremely slow process and it led to less dark olives. Although the ferric ions were able to darken the colour of the washing waters, their high molecular structures formed during the oxidation of the ferrous gluconate solution to ferric state limited their penetration into the olive flesh, and thus the formation of coloured iron complexes. The results presented in this study suggest that the formation of ferric ions during the colour fixation step of black ripe olives must be avoided to get darker olives.

\section{ACKNOWLEDGEMENTS}


291 This work was supported by the Spanish Government Projects AGL2013-42739-R and 292 AGL2016-76820-R (AEI/FEDER, UE).

293

294

295

296

297

298

299

300

301

302

303

304

305

306

307

308

309

310

311

312

313

314

3. Papadaki E and Mantzouridou F T, Current status and future challenges of table olive processing wastewater valorization. Biochem Eng J 112:103-113 (2016).

4. Brenes $\mathrm{M}$, Romero $\mathrm{C}$ and García $\mathrm{P}$, Optimization of ripe olive processing with a single lye treatment. J Food Sci 82:2078-2084 (2017).

5. International Olive Council (IOC), Unified qualitative standard applicable for table olives in international trade. Madrid. Spain (2004).

6. Brenes M, Romero C, García P and Garrido A, Effect of $\mathrm{pH}$ on the colour formed by Fe-phenolic complexes in ripe olives. J Sci Food Agric 67:35-41 (1995).

7. García P, Brenes M, Romero C and Garrido A, Colour fixation in ripe olives. Effects of type of iron salt and other processing factors. J Sci Food Agric 81:1364-1370 (2001).

8. García P, Sánchez A H and Garrido A, Changes of physicochemical and sensory characteristics of packed ripe table olives from Spanish cultivars during shelflife. Int J Food Sci Technol 49:895-903 (2014).

9. Andjelkovic M, Van Camp J, De Meulenaer B, Depaemelaere G, Socaciu C, Verloo $\mathrm{M}$ and Verhe $\mathrm{R}$, Iron-chelation properties of phenolic acids bearing catechol and galloyl groups. Food Chem 98:23-31 (2006). 
10. Zamora R and Hidalgo F J, The triple defensive barrier of phenolic compounds against the lipid oxidation-induced damage in food products. Trends Food Sci Technol 54:165-174 (2016).

11. Catrouillet C, Davranche M, Dia A, Bouhnik-Le Coz M, Marsac R, Pourret O and Gruau G, Geochemical modelling of Fe (II) binding to humic and fulvic acids. Chem Geol 372:109-118 (2014).

12. Perron N R, Wang H C, De Guire S N, Jenkins M, Lawson M and Brumaghim J L, Kinetics of iron oxidation upon polyphenol binding. Dalton Trans 39:99829987 (2010).

13. Nkhili E, Loonis M, Mihai S, El Hajji H and Dangles O, Reactivity of food phenols with iron and copper ions: binding, dioxygen activation and oxidation mechanism. Food Funct 5:1186-1202 (2014).

14. De Castro A, García P, Romero C, Brenes $M$ and Garrido A, Industrial implementation of black ripe olive storage under acidic conditions. J Food Eng 80:1206-1212 (2007).

15. Romero C, García-García P and Brenes M, Enrichment of black ripe olives in bioactive compounds using a single alkali treatment. J Food Sci 81:C2686C2691 (2016).

16. Albi M A and Garrido A, Black ripe olives. III. Comparative study of methods to analyse iron in olives. Grasas y Aceites, 26:133-135 (1975).

17. Luan F and Burgos W D, Sequential extraction method for determination of Fe II/III and U (IV/VI) in suspensions of iron-bearing phyllosilicates and uranium. Environ Sci Technol 46:11995-12002 (2012).

18. Vincenzo M, Campestre C and Lanza B, Phenolic compounds change during California-style ripe olive processing. Food Chem 74:55-60 (2001). 


\section{Figure captions}

Figure 1. Evolution of total iron, Fe (II) and Fe (III) in the ferrous gluconate solutions in contact with olives during the colour fixation step when the initial $\mathrm{pH}$ was corrected to 4 units or not corrected. Bars mean the standard deviation.

Figure 2. Influence of the initial $\mathrm{pH}$ correction up to 4 units on the evolution of this parameter in the ferrous gluconate solution used for the colour fixation of black ripe olives. Bars mean the standard deviation.

Figure 3. Influence of $\mathrm{pH}$ on the evolution of iron species during oxidation of a ferrous gluconate solution of $1 \mathrm{~g} \mathrm{~L}^{-1}$. The solutions were aerated at $20^{\circ} \mathrm{C}$ for six hours.

Figure 4. Evolution of the colour and iron concentration of black ripe olives during the colour fixation step in a ferrous gluconate solution with and without initially corrected the $\mathrm{pH}$. Bars mean the standard deviation.

Figure 5. Colour of olives and iron content in both ferrous and ferric solutions during the colour fixation step at $\mathrm{pH} 4.5$. The ferrous solution had $92 \% \mathrm{Fe}$ (II) and the ferric $75 \% \mathrm{Fe}$ (III). Bars mean the standard deviation. 
Table 1 Influence of iron oxidation status on the colour of a washing solution from black ripe olive processing. A mixture of this washing solution with a ferrous or ferric solution (1:4) was studied at $\mathrm{pH} 4.5$ for five hours.

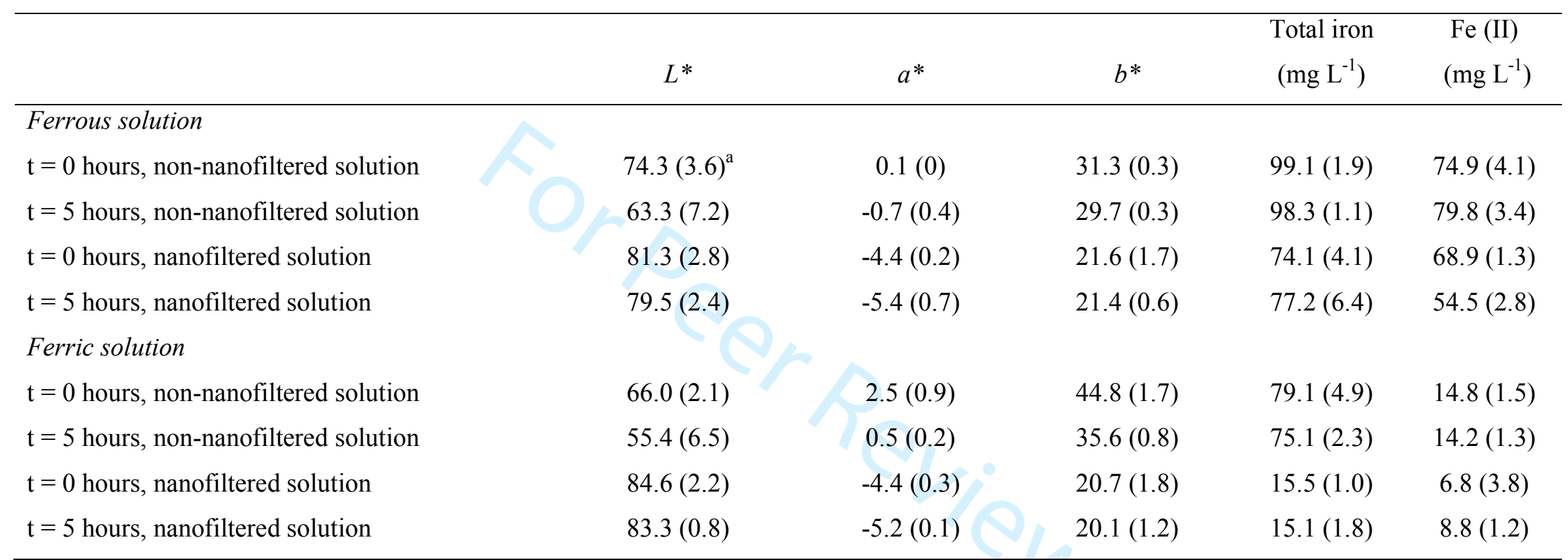

${ }^{\mathrm{a}}$ Standard deviation is shown between parentheses. Colour parameters of a mixture (1:4) of the washing solution and distilled water at $\mathrm{pH} 4.5$ were the following: $L^{*}=84.3(0.6), a^{*}=1.9(0.1), b^{*}=33.0(0.3)$. 


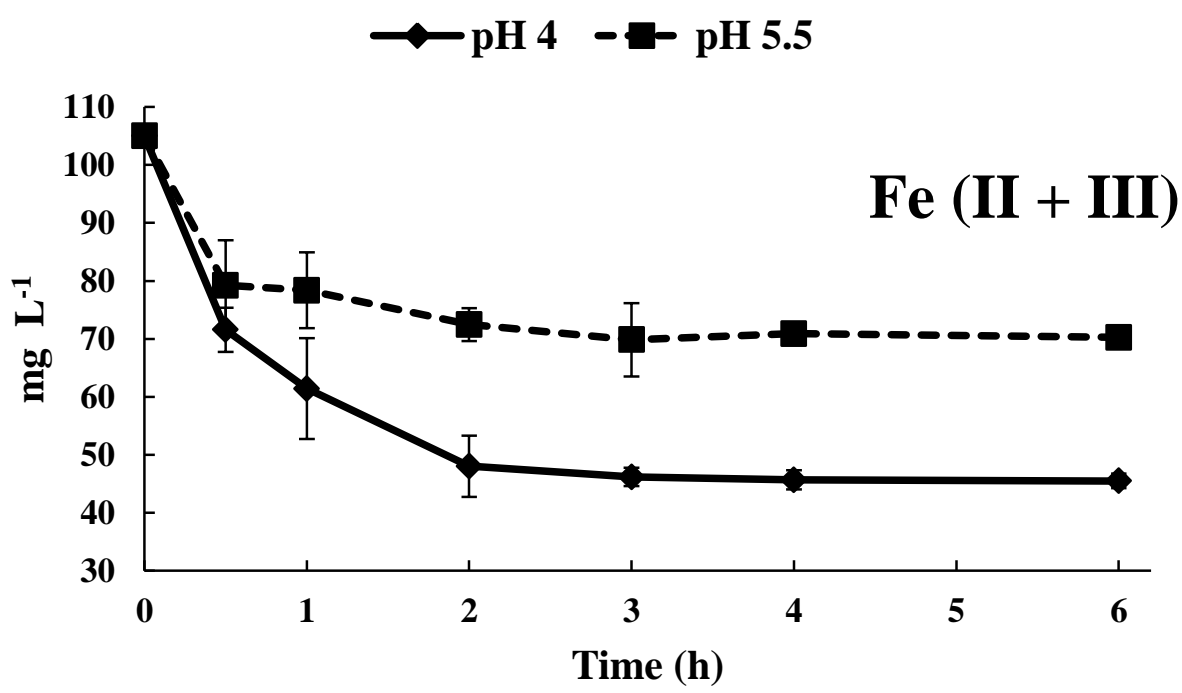

$\sim$ pH $4-$ - pH 5.5
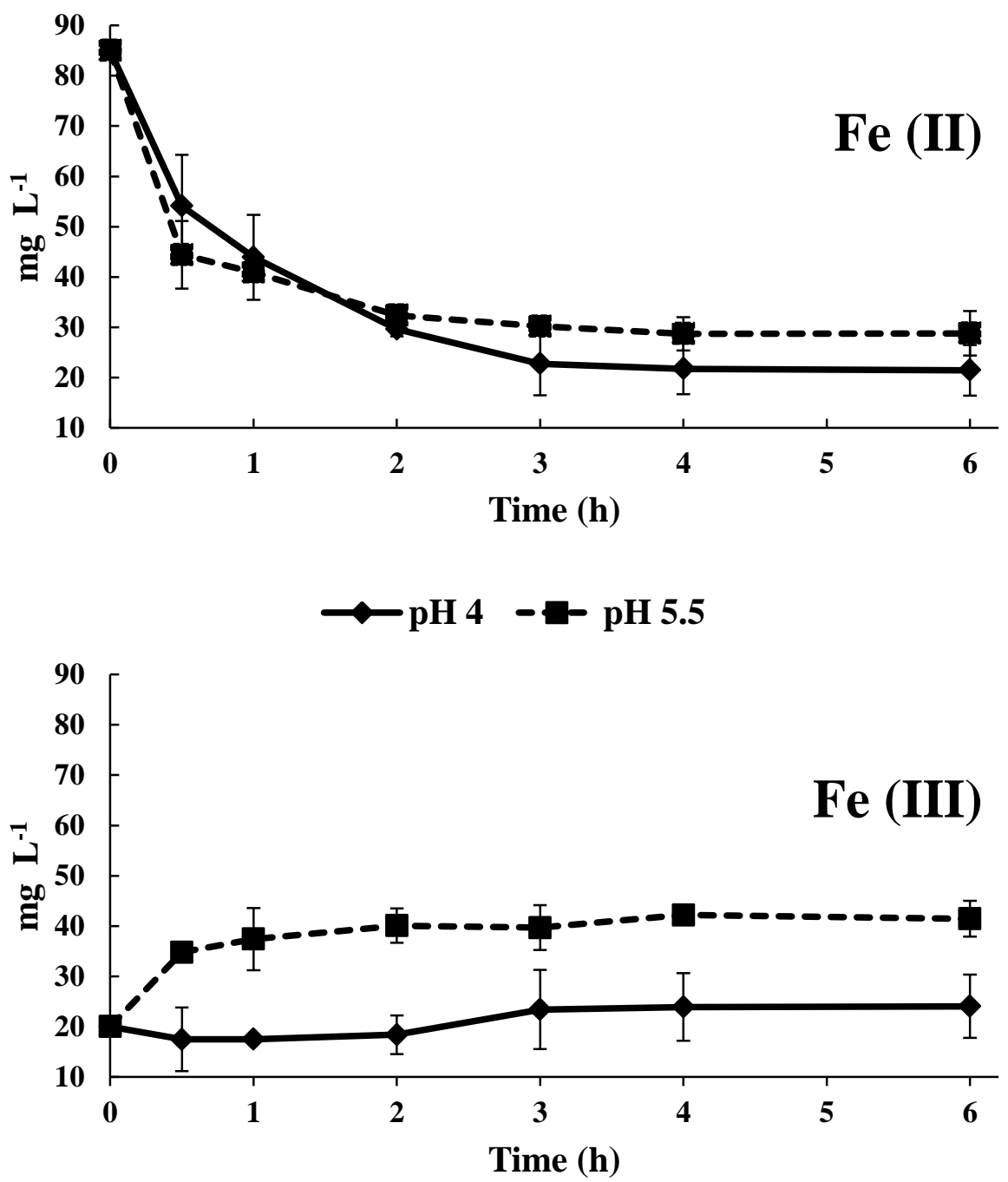

JSFA@wiley.com 
$\leadsto$ pH $4 \rightarrow$ pH 5.5

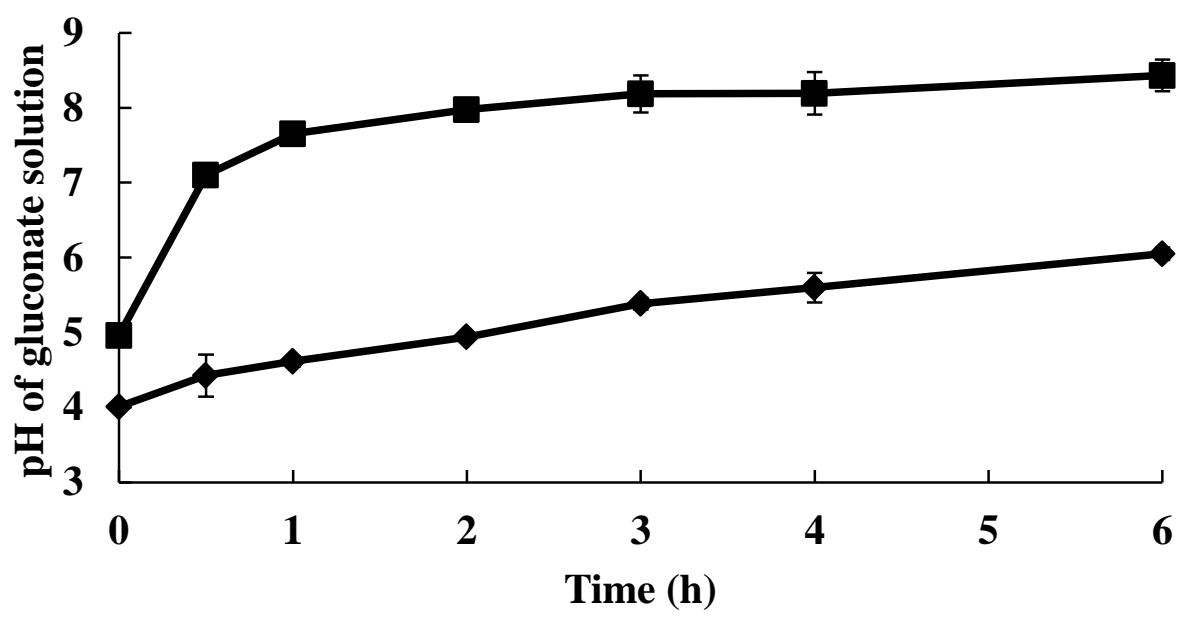



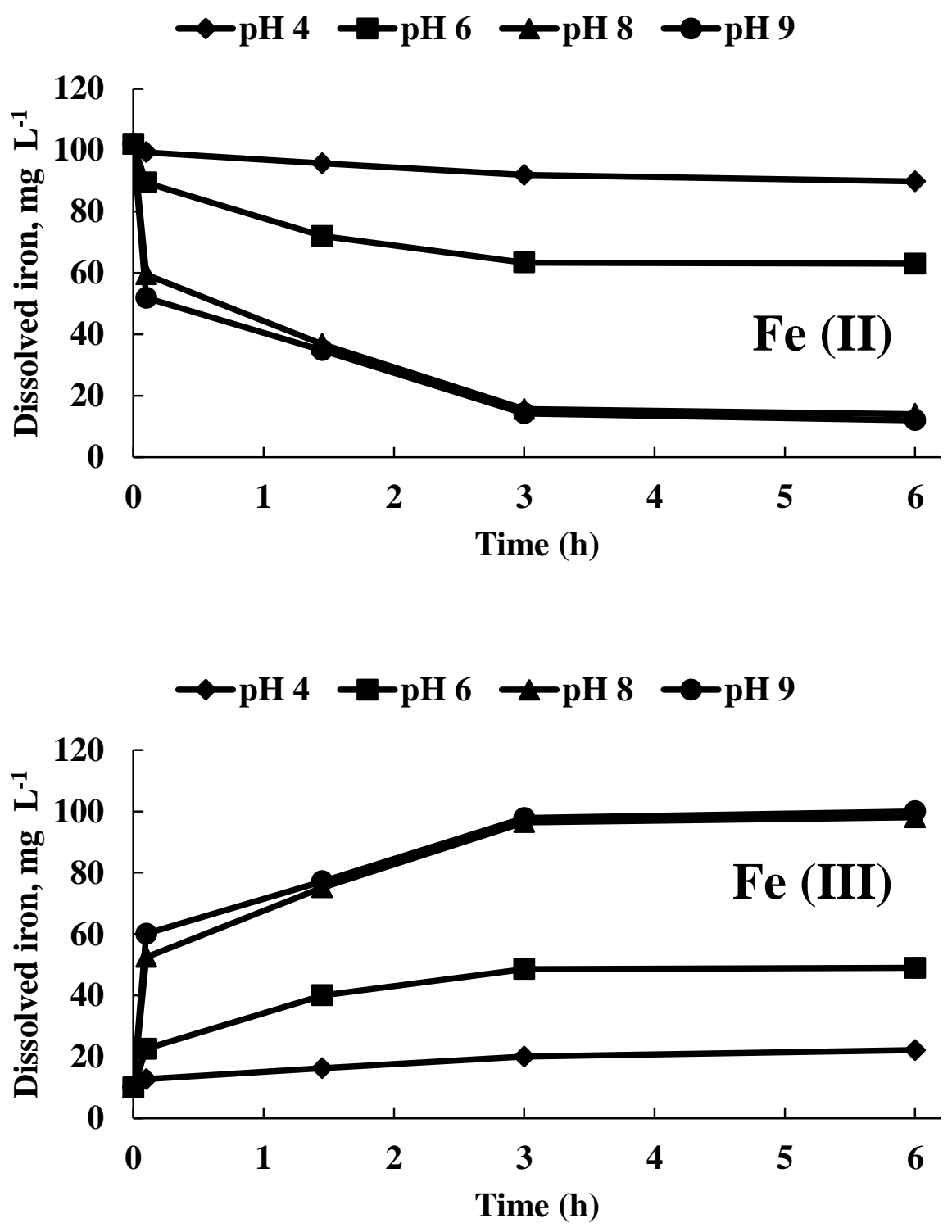
$\neg$ pH $4-6$ pH 5.5

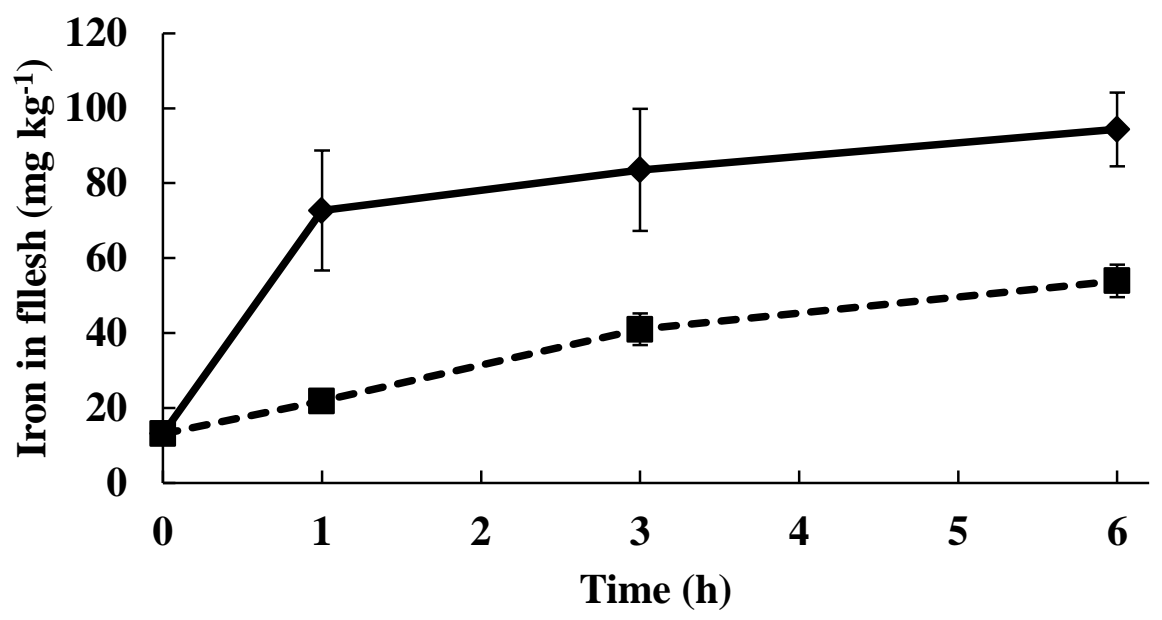

$\checkmark$ pH $4-2$ pH 5.5

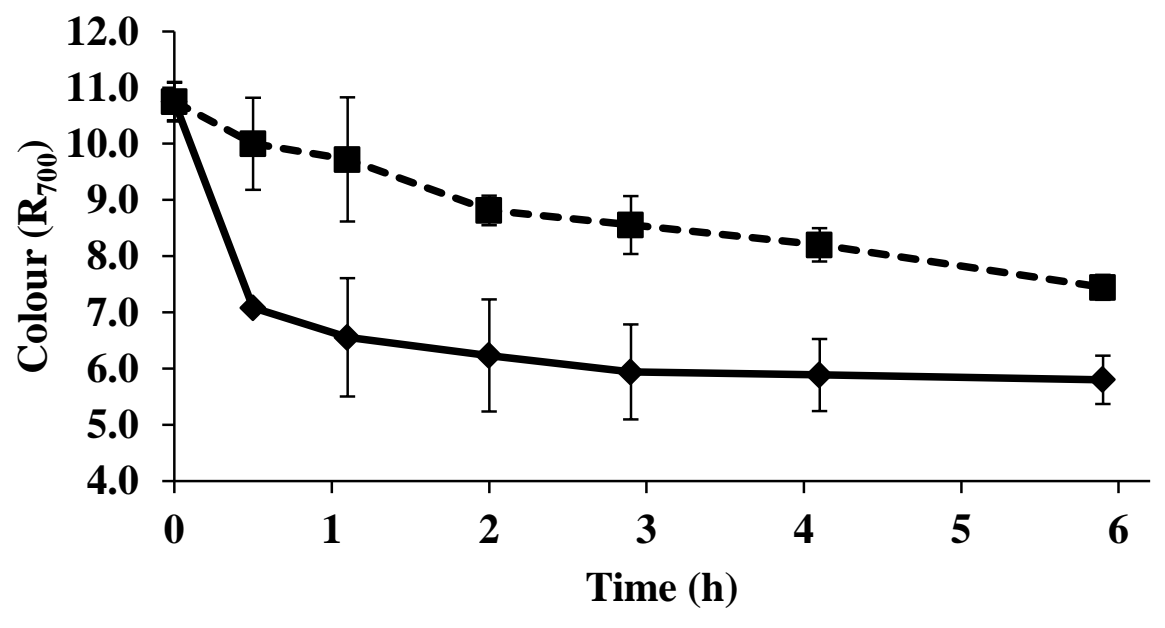

37

38

39

40

41

42

43

44

45

46

47

48

49

50

51

52

53

54

55

56 
$\sim$ Ferrous solution $\quad-$ Ferric solution


Time (h) 